\title{
СИНТАКСИЧЕСКИЕ ПРЕОБРАЗОВАНИЯ И ПРОБЛЕМА МЕЖЬЯЗЫКОВОЙ АСИММЕТРИИ ПРИ ПЕРЕВОДЕ БИОГРАФИИ С АНГЛИЙСКОГО ЯЗЫКА НА РУССКИЙ
}

\section{SYNTACTIC TRANSFORMATIONS AND THE PROBLEM OF INTERLINGUAL ASYMMETRY IN TRANSLATION OF THE BIOGRAPHY FROM ENGLISH INTO RUSSIAN}

\section{E. Andreeva}

Summary: The article is devoted to the problem of the inevitable asymmetry in the systems of means of expression between the original language and the translating language that occurs in translation of the biography text from English into Russian. Cases of mixed types of the major syntactic transformations are considered and their functions are analyzed in the light of peculiarities of the translating language. Examples are given by the author from the English and Russian versions of the biographical research by American writer and publicist Peter Kurth "Isadora:f A Sensational Life".

Keywords: translation, translation equivalence, interlingual asymmetry, syntactic transformations, translation adequacy.
$\mathrm{B}$ современной лингвистике существует большое количество подходов к переводу художественного текста. Стоит начать с того, что понятие «перевод» определяется различными исследователями поразному.

В.Н. Комиссаров полагает, что перевод представляет собой определённый тип языкового посредничества, «при котором на ПЯ (переводящем языке) создается текст, коммуникативно равноценный оригиналу, причём его коммуникативная равноценность проявляется в его отождествлении рецепторами перевода с оригиналом в функциональном, содержательном и структурном отношении» $[6$, c. 45]. Из данного определения следует мысль о том, что основная задача, стоящая перед переводчиком, заключается в достижении адекватности перевода посредством максимально точной передачи содержания оригинала средствами переводящего языка.

В.С. Виноградов подчёркивает близость перевода как вида человеческой деятельности к искусству: «Нужно согласиться с мыслью, что перевод - это особый, своеобразный и самостоятельный вид словесного искусства. Это искусство «вторичное», искусство «перевыражения»

\author{
Андреева Екатерина Юрьевна \\ Аспирант, Московский государственный университет \\ имени М.В. Ломоносова \\ katerina88557@yandex.ru
}

Аннотация: Данная статья посвящена проблеме неизбежной асимметрии систем средств выражения языка оригинала и переводящего языка, в0зникающей в процессе перевода текста биографии с английского на русский. Рассматриваются случаи смешения базовых видов синтаксических трансформаций, а также анализируются их функции с учётом особенностей переводящего языка. Автором приводятся примеры из англоязычной и русской версий биографического исследования американского писателя и публициста Питера Курта «Айседора. Неистовый танец жизни» ("Isadora: A Sensational Life").

Ключевые слова: перевод, эквивалентность перевода, межъязыковая асимметрия, синтаксические трансформации, адекватность перевода. оригинала в материале другого языка» [3, с. 8]. Французский теоретик перевода Ж. Мунен также называет перевод искусством, которое базируется на науке [10]. Искусство же переводчика сосредоточено в том, чтобы «создать новое произведение в иной семиотической системе, для иной культурной среды, иногда и для иной эпохи» [5, с. 357].

Приступая к переводу произведения с одного языка на другой, переводчик должен учитывать специфику преобразования оригинального текста. Речь идёт об одном из важнейших вопросов современного переводоведения - проблеме эквивалентности текста-источника и его переведённой версии. Необходимо отметить тот факт, что при переводе «существенной является эквивалентность значений не отдельных слов и даже не изолированных предложений, но всего переводимого текста в целом по отношению ко всему тексту перевода» [2, с. 15]. Под эквивалентностью традиционно понимают «взаимозаменяемость сравниваемых объектов» [4, с. 28]. Важно заметить, что данная взаимная заменяемость элементов никогда не может являться абсолютной ввиду асимметрии систем средств выражения языка оригинала и переводящего языка. Ввиду того, что «система смыслов 
исходного текста и система смыслов текста перевода никогда или почти никогда не бывают абсолютно симметричными» [5, с. 369], можно заключить, что межъязыковая асимметрия - неизбежное и единственно возможное отношение между оригинальным текстом и его переводной версией.

Непосредственный процесс перевода произведения с одного языка на другой определяется как процесс межъязыковой трансформации. Термин «трансформация» получил широкое распространение в современной лингвистике, отображая отношения между исходными и конечными языковыми выражениями посредством замены одной формы выражения на другую при переводе того или иного произведения.

Что касается синтаксических трансформаций, их можно определить как изменения «схемы мысли» автора оригинального произведения в процессе перевода [5]. Переходя непосредственно к основным типам синтаксических преобразований, которые используются при художественном переводе (перестановки, замены, добавления, опущения) [1; 8], в первую очередь следует обратить внимание на специфику порядка слов в предложениях переводящего языка. Дело в том, что порядок слов в русском предложении чаще всего определяется особыми факторами, связанными с «коммуникативным членением»: «новое» (слова, передающие информацию, которая сообщается впервые) обычно помещается в конец предложения, а «данное» (слова, которые передают известную из предшествующего контекста информацию) оказывается в начале. Приведём несколько примеров, иллюстрирующих данное положение:

"Born in Philadelphia in 1819, Joseph Duncan was effectively of the same generation as Isadora's grandfather, Colonel Gray, and his early life reflects the same pioneer spirit and continual migration: from Philadelphia to Maryland, New York, Illinois, New Orleans, and, finally, San Francisco." [9, p. 8] / "Джозеф Дункан, родившийся в Филадельфии в 1819 году был плоть от плоти того же поколения, что и дедушка Айседоры полковник Грэй, и в начальном периоде его жизни отразился всё тот же первопроходческий дух и скитальческая жизнь: из Филадельфии в Мэриленд, Нью-Йорк, Иллинойс, Новый Орлеан и, наконеи, Сан-Франциско». [7, с. 15].

Данный пример является иллюстрацией использования перестановки с целью выделения основного смысла частей предложения. Помимо перестановки, переводчик также производит замену наречия 'effectively' фразеологизмом 'nлоть от плоти', несущим идею необыкновенного сходства поколений. Также С. Лосев заменяет оригинальное словосочетание 'continual migration' сочетанием 'скитальческая жизнь' с целью выразительного описания беспокойной, полной переездов из города в город жизни отца Айседоры Дункан. Наконец, переводчик трансформирует синтаксическую структуру предложения оригинала: в английской версии вторая часть сложносочинённого предложения содержит подлежащее 'life' и дополнения 'spirit' и 'migration', в то время как в переводе 'Әух' и 'жизнь' являются подлежащими.

"The Dutch had never been known as lovers of dance; Isadora may be said to have made them so." [9, p. 185] / «Голландцы никогда не слыли любителями танца - пожалуй, можно сказать, что Айседора сделала их таковыми». [7, с. 252].

В данном случае переводчиком используется такой вид трансформационной операции, как замена. С. Лосев заменяет пассивную конструкцию 'had never been known' более привычной для русскоговорящих читателей активной 'никогда не слыли'. То же самое происходит с оригинальным предложением, содержащим в себе специфичную для английского языка конструкцию 'complex subject' ('may be said to have made'): переводчик меняет английское предложение с данной структурой на русское сложноподчинённое предложение, в котором главное предложение односоставно (безличное предложение) и придаточное двусоставно (сказуемое выражено глаголом в активном залоге). Таким образом, данные замены обусловлены нормами русского языка.

"In her autobiography, Isadora fudges dates and improves the tale, but she hardly exaggerates the atmosphere of storm that attended her first months of life." [9, p. 11] / «B автобиографии Айседора часто путает даты и приукрашивает, но едва ли преувеличивает, повествуя о тяжёлой атмосфере, окружавшей её колыбельку в первые месяцы жизни». [7, с. 20].

Из данного примера видно, что переводчик добавляет деепричастный оборот 'повествуя о тяжёлой amмосфрере', а также причастный оборот 'окружавшей её колыбельку'. Эти добавления несут в себе эмоциональную нагрузку, очень ярко отображая настроение, царящее в доме главной героини биографии сразу после её рождения, и придают тексту перевода образность. Определение 'her' и дополнение 'the tale' исключаются переводчиком как семантически избыточные единицы.

Рассмотрев различные случаи смешения основных видов синтаксических преобразований в переводе биографии "Isadora: A Sensational Life", а также определив цели их использования, можно прийти к следующим выводам: 
1. отношение асимметрии между оригинальным текстом и текстом перевода биографии неизбежно в силу расхождений в формальной и семантической системах английского и русского языков;

2. комплексные синтаксические трансформации используются переводчиком с целью достижения адекватности перевода. Учёт особенностей коммуникативного членения в русском языке, исключение семантически избыточных слов из структуры предложения, использование типичных для русского языка конструкций - всё это средства переводящего языка, помогающие переводчику максимально полно отобразить глубинную структуру оригинального текста;

3. некоторые межъязыковые преобразования способны придавать экспрессивность исходному тексту.

Проблемы, затронутые в настоящей статье, могут послужить поводом для дальнейшего изучения синтаксических средств, используемых при переводе биографий известных людей с английского языка на русский.

\section{ЛИТЕРАТУРА}

1. Бархударов Л.С. Язык и перевод (Вопросы общей и частной теории перевода). - М.: Советский писатель, 1975. - 238 с.

2. Бархударов, Л.С. Язык и перевод: Вопросы общей и частной теории перевода. Изд. 2-е. - М.: Издательство ЛКИ, 2008. - 240 с.

3. Виноградов В.С. Лексические вопросы перевода художественной прозы. - М.: Изд-во МГУ, 1978. - 174 с.

4. Гарбовский Н.К. О теоретических взглядах на категорию переводческой эквивалентности // Язык, культура и межкультурная коммуникация. Межвузовский сборник статей. - М.: Изд-во Моск. ун-та, 2001. - с. 26-44.

5. Гарбовский Н.К. Теория перевода: Учебник. - 2-е изд. - М.: Изд-во Моск. ун-та, 2007. - 544 с.

6. Комиссаров В.Н. Теория перевода (лингвистические аспекты). - М.: Высшая школа, 1990. - 253 с.

7. Курт П. Айседора. Неистовый танец жизни. Пер. с англ. С. Лосева. - М.: Изд-во Эксмо, 2002. - 768 с.

8. Львовская 3.Д. Теоретические проблемы перевода. - М.: Высш. шк., 1985. - 232 с.

9. Kurth, Peter. Isadora: A Sensational Life. - 1st ed. - Boston: Little, Brown and Company, 2001. - 704 p.

10. Mounin, Georges. Les problèmes théoriques de la traduction. Paris: Gallimard, 1963. - 296 p.

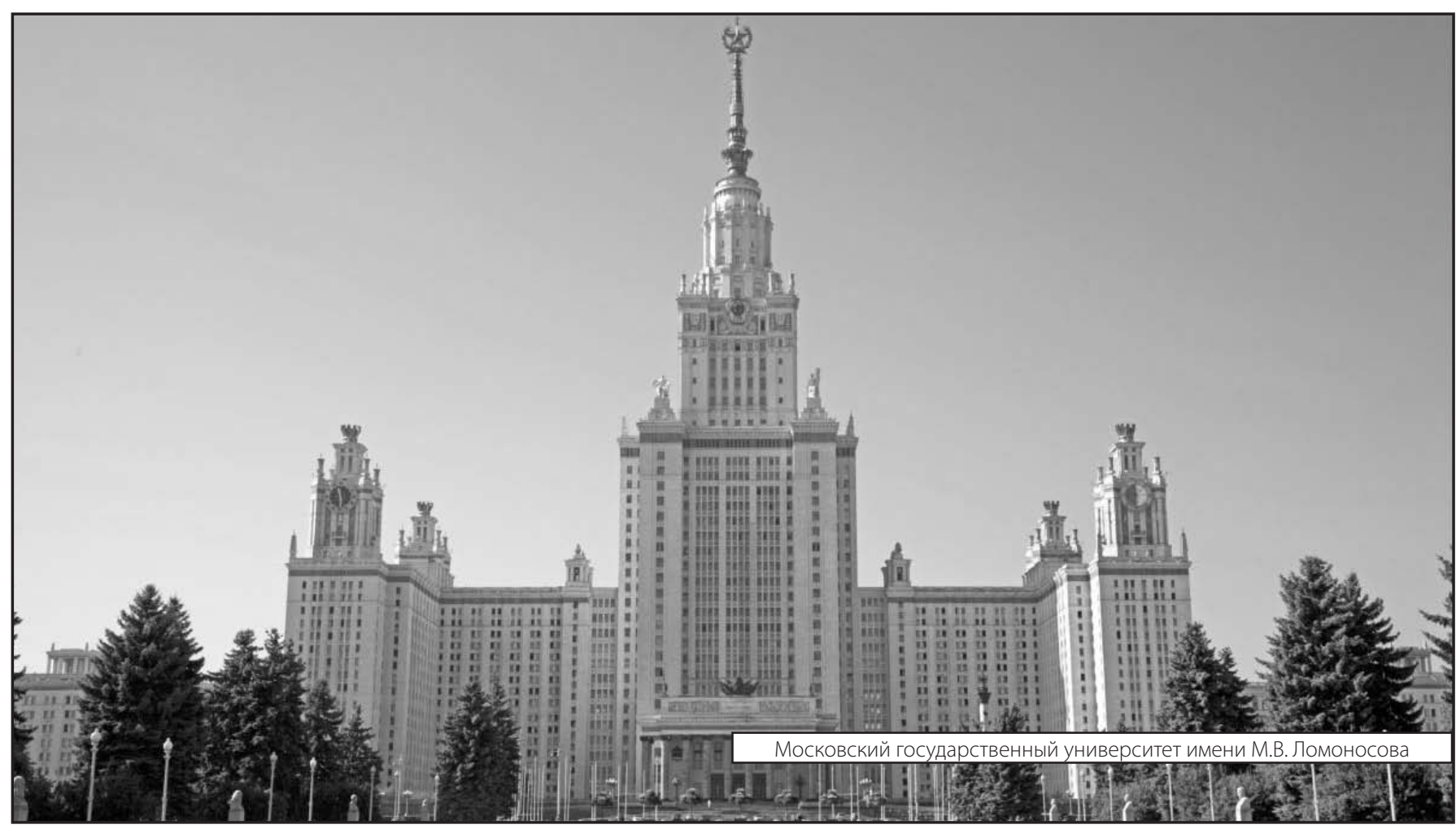

